it is not now considered necessary to observe many stars fainter than magnitude 8 on the meridian; the positions of fainter stars are obtainable by photography with lenses of wide angle.

Observations with the Cookson floating zenith telescope now cover a period of nineteen years, which is the period of the great lunar nutation term. Dr. J. Jackson is discussing the observations, to deduce a new value for the coefficient of this term; it appears that the adopted value $9 \cdot 210^{\prime \prime}$ will not be altered by more than 0.002 ". The Gerrish drive, installed last year on the 28 -inch equatorial, has worked very well. 300 binaries were observed during the year, of which 56 were separated by less than $\frac{1}{2}$.

The determination of stellar parallaxes by photography with the Thompson equatorial has proceeded at an accelerated pace, 1508 parallax plates having been taken, and 651 plates measured.

The determination of the 'colour-temperatures' of stars has been continued with the 30 -inch reflector. The observation of 24 star's selected as standards has been completed ; these are now available as a base to which other stars can be referred. The absolute temperatures of the standards are now being found by comparison with an are lamp, which in turn will be compared with a gas-filled lamp already calibrated at Utrecht.

The astrographic equatorial, which had been sent to Siam for the solar eclipse, was remounted in July. Some renewals in the bearings and accessories were satisfactorily carried out by Messrs. Grubb, Parsons and Co. The Greenwich astrographic zone, decl. $64^{\circ}$ to $90^{\circ}$, is being re-photographed for the determination of proper motions by comparison with the earlier plates; the motions of 14,500 stars between $64^{\circ}$ and $72^{\circ}$ have now been published.

The sun was photographed on 270 days at Greenwich; plates taken at the Cape and Kodaikanal will render the record complete. The spot activity is definitely on the wane; there were, however, large spots in November and December. A spectrohelioscope has been lent to the Observatory by the Mount Wilson Observatory; it has been mounted in the south attic of the new building. A survey of the sun's disc in $H_{\alpha}$ light is made daily, when weather permits. Special attention is paid to the radial velocities of dark markings near sunspots.

Spot numbers for the whole dise, and for the central zone, are supplied regularly to Zurich for incorporation in the bulletin that is issued there under the auspices of the I.A.U.

The mean temperature of the year was $51 \cdot 0^{\circ}$, which is $1.5^{\circ}$ above the 75 -year average ; the extreme values were $90.5^{\circ}$ on Aug. 31 , and $25.4^{\circ}$ on Mar. $20 ;$ both dates are unusually late for the extreme readings. The rainfall was 25.43 inches, which is 1.19 in. above the average. The winter was a stormy one, and the mean daily air movement, 289 miles, is 5 miles above the average. The highest daily value was 847 miles on Dec. 7 ; the highest hourly value 62 miles on Jan. 12, which also had the greatest pressure, $38 \mathrm{lb}$. per sq. ft.

The following are the mean values of the magnetic elements for 1929, obtained at Abinger; Decl. $12^{\circ} 35 \cdot 8^{\prime}$ W.; Hor. Force 0.18555: Vert. Force $0 \cdot 42918$ : $\mathrm{Dip} 66^{\circ} 37 \cdot 2^{\prime}$. It is noted in the report that a more precise instrument for determining the vertical force and dip was lent by the National Physical Laboratory; it revealed a small systematic error in the values given by the dip inductor; the error was 0.00010 in Vert. Force, $0.3^{\prime}$ in Dip.

The performance of the Shortt clocks continues to be satisfactory; in the sidereal clock No. 3 an invar bob was substituted for the type-metal one; the latter contained lead, and a certain amount of settling appears to have gone on, causing an increase of losing rate. This increase still goes on with the new bob, but at only half the former rate.

Rhythmic time signals from the Observatory are distributed by the wireless station at Rugby at $10 \mathrm{~h}$. and $18 \mathrm{~h}$. These, and the signals sent to the Post Office and the B.B.C., are controlled by the clock Shortt No. 16.

The following are the mean amounts by which the time signals from other stations are late on Greenwich: Paris 0.044 sec. : Nauen 0.006 sec.: Annapolis (near Washington) $0.007 \mathrm{sec}$. Bordeaux $0.035 \mathrm{sec}$. These are after corrections for lag and time of travel have been applied.
A. C. D. Crommelin.

\title{
An Early Letter from Darwin to Owen.
}

THE letter printed below was bought at Sotheby's in March of this year for the Fitzwilliam Museum, Cambridge, by some friends of that institution. It was written rather more than two months after Darwin's return in the Beagle. The fossil vertebrates referred to in the letter were sent to the Royal College of Surgeons. Darwin wrote to Owen, who was five years his senior, as a young man addressing a more experienced and older colleague: later the two became friends and Owen visited Down in 1848. Twelve years later, in a letter to de Quatrefages, Darwin wrote: "I have been atrociously abused by my religious countrymen; but as I live an independent life in the country, it does not in the least hurt me in any way, except indeed when the abuse comes from an old friend like Professor Owen, who abuses me and then advances the doctrine that all birds are probably descended from one parent" ("More Letters of Charles Darwin ", vol. 1, p. 202). Reference is made to Darwin's attitude towards Owen in a note printed at the head of a letter to Hugh Falconer (1863) on page 226 of vol. 2 of "More Letters".

Darwin settled at Cambridge on Dec. 10, 1836 : he was at first a guest in the home of the Henslows, and later went into lodgings at a house in Fitzwilliam Street, on which a tablet has been fixed. The letter was written as from Christ's College, though he was presumably not actually in residence there.

A. C. S.

My dear Sir,

Decemb 19th (1836)

I have just written and will send it the same time with this, a letter to Sir Ant: Carlisle. I have done exactly as you recommended me. I thought myself compelled to fix on the British Museum in preference to that of Paris because I was carried on board a King's Ship ; and the public collection of the country certainly has claims on me. If the collection had been made entirely at my own expense, that is on board a Merchant vessel, then I should not have hesitated in making a different choice. I quite agree with you that the British Museum ought to make returns when it has the power. I suppose you could not venture to propose another set for Paris. Their value would be so much more in that collection than in the British Museum. I ought to make up my mind to give my own set to Paris; but I confess I should be grieved to lose my trophies. I should feel like a knight who had lost his armorial bearings. If the Council should not choose to go to the expense necessary for making all the casts; it was suggested to me here, that the 